\title{
Pulmonary blood volume variation indexed to stroke volume and perfusion gradients: novel diagnostic tools in heart failure
}

\author{
Mariam Al-Mashat, Mikael Kanski, Jonas Jögi, Håkan Arheden \\ From 19th Annual SCMR Scientific Sessions \\ Los Angeles, CA, USA. 27-30 January 2016
}

\section{Background}

Heart failure (HF) is a condition characterized by increased filling pressures in the left ventricle due to altered cardiopulmonary blood flow. However, there are no clinically available non-invasive quantitative methods to measure filling pressures in HF. The pulmonary blood volume variation (PBVV) indexed to stroke volume (SV) by cardiac magnetic resonance (CMR) could be a novel non-invasive measure of HF. However, the relationship between PBVV/SV and increased filling pressures has not been validated. We have previously shown that the effect of increased filling pressures and redistribution of pulmonary blood flow can objectively be quantified using perfusion gradients derived from ventilation/perfusion single-photon emission computed tomography (V/P SPECT). V/P SPECT perfusion gradients have a high positive predictive value to diagnose decompensated HF.

The aim of this study was therefore to investigate the relationship between the PBVV/SV and perfusion gradients in patients with heart failure.

\section{Methods}

Fifteen patients with HF (NYHA class 2-4, 2 women, 48-77 years) were included. All patients underwent CMR at $1.5 \mathrm{~T}$ and V/P SPECT. Four patients were under consideration for heart transplantation and 11 patients were candidates for cardiac resynchronization therapy. By measuring the blood flow in the pulmonary trunk and in one pulmonary vein, the PBVV was calculated, defined as the maximum cumulative difference in pulmonary blood volume over one heart beat. The SV by

Department of Clinical Physiology, Skane University Hospital, Lund University, Lund, Sweden 
measures of HF. Further validation work with comparison to invasive pressure measurements are needed to assess the accuracy of the methods.

Published: 27 January 2016

doi:10.1186/1532-429X-18-S1-Q23

Cite this article as: Al-Mashat et al:: Pulmonary blood volume variation indexed to stroke volume and perfusion gradients: novel diagnostic tools in heart failure. Journal of Cardiovascular Magnetic Resonance 2016 18(Suppl 1):Q23.

Submit your next manuscript to BioMed Central and take full advantage of:

- Convenient online submission

- Thorough peer review

- No space constraints or color figure charges

- Immediate publication on acceptance

- Inclusion in PubMed, CAS, Scopus and Google Scholar

- Research which is freely available for redistribution

Submit your manuscript at www.biomedcentral.com/submit 